\title{
Criss-cross Heart: A Complex Congenital Heart Disease
}

\author{
Begum NNF ${ }^{1}$, Ferdous $\mathrm{J}^{2}$
}

DOI: https://doi.org/10.3329/jafmc.v14i2.45913

\begin{abstract}
A criss-cross heart is a rare congenital heart disease that is commonly associated with complex cardiac defect. Criss-cross heart is characterized by crossing of the inflow streams of the two ventricles, due to twisting of the heart during development. As a result the axis of the openings of the atrioventricular (AV) valves remain non parallel. We report a case of 2.5 months old baby with criss-cross spatial relationship of the atrioventricular valve with double outlet right ventricle with Pulmonary Artesia and atrial and ventricular septal defect. The diagnosis was confirmed by $2 \mathrm{D}$ and color Doppler Echocardiography in subxiphoid long-axis and coronal plane sweeps. Due to the complex structural changes and rarity of the anomaly, the diagnosis is often missed. In this case report we emphasized on diagnosis feature of presentation and surgical techniques required to correct or palliate the defects.
\end{abstract}

\section{Introduction}

Criss-cross heart is a rare congenital heart defects accounting for morethan $0.1 \%$ of all congenital heart diseases (CHD). The morphological essence of the criss-cross heart is a rotation of ventricular mass along with major axis resulting in different relationships and connections between the atria, ventricle and great vessels. Atrioventricular concordance and ventriculoarterial discordance are seen in $80 \%$ of cases. A ventricular Septal defect is seen in almost all the cases. Other anomalies such as pulmonary stenosis, straddling of atrioventricular valves, tricuspid atresia, double outlet right ventricle and congenitally corrected transpositions are seen.

\section{Case Report}

Baby-X, a 2.5 month's old female infant, weighting $4.3 \mathrm{~kg}$ presented with history of respiratory distress, feeding difficulty and cyanosis since one month of age. Baby was 1 st issue of consanguineous marriage and born by caesarean delivery. There was no family history of congenital heart disease. Physical examination revealed evidence of cyanosis, pallor, tachycardia with heart rate $120 / \mathrm{min}$, tachypnea with respiratory rate $50 / \mathrm{min}$, blood pressure $75 / 40 \mathrm{~mm}$ of $\mathrm{Hg}$, peripheral pulses were present and symmetrical with surface oxygen saturation of $40-50 \%$ in room air. Cardiac auscultation revealed normal first and second heart sound along with a grade $3 / 6$ ejection systolic murmur best audible atright upper parasternal area. Provisional diagnosis was complex congenital heart disease. Chest X-ray showed oligaemic lung field with Mesocardia,
ECG showed right ventricular hypertrophy and thorough echo study showed Mesocardia, L- loop ventricle. Left sided left atrium and right sided left ventricle connected through the mitral valve, right sided right atrium (RA) was connected to left sided right ventricle through tricuspid valve. So ventricles were L-looped with concordant atrioventricular and discordant ventriculoarterial connection. Aorta was arising from RV and PA was also committed to right side. Main pulmonary artery was not seen (Pulmonary atresia) and small Patent ductusarteriosus (PDA) was seen supplying small pulmonary arteries. Large atrial septal defect (ASD secundum type) and large inlet ventricular septal defect (VSD) was noticed. So final diagnosis was Mesocardia, L-loop,Criss cross heart with double outlet right ventricle (DORV) with pulmonary artesia (PA) with PDA dependent pulmonary circulation, large ASD secundum andlarge inlet VSD.

Initially patient was managed by giving treatment of adequate nutrition and hydration with management of cyanotic spellby: $\mathrm{O}_{2}$ inhalation, normal saline infusion and injection Esmolol. Aantibiotics: injection Meropenum and Prophylaxis against spell by tab Propranolol and Phenobarbitone. As patients pulmonary blood flow was inadequate, immediate palliation to maintain pulmonary blood flow was planned and referred to advanced cardiac center of India as native surgeons refused the case. PDA anatomy was not suitable for stenting. Plan of surgery from pediatric cardiologists were; Blalock Taussig shunt (BT shunt) in first stage then Single ventricle/ biventricular repair later.

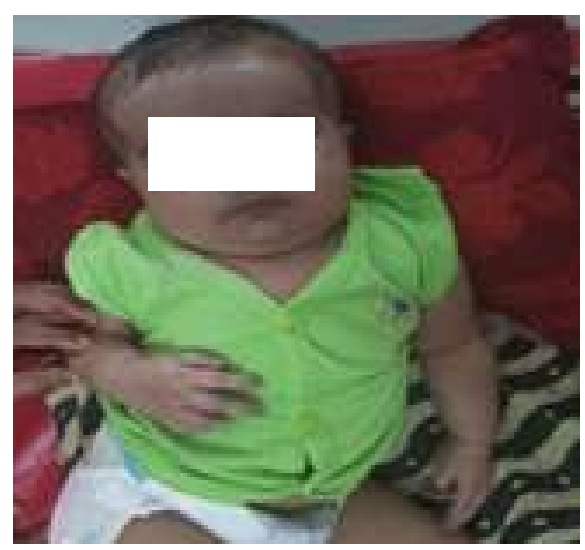

Figure-I: Baby-X

1. Brig Gen Nurun Nahar Fatema Begum, SBP, MBBS, FCPS, FRCP, FACC, FSCAI, Independence Awardee, Professor \& Head of the Department of Paediatrics, Armed Forces Medical College, Dhaka (E-mail: colfatema@hotmail.com) 2. Lt Col Jannatul Ferdous, MBBS, FCPS, Classified Specialist in Paediatrics, CMH, Dhaka. 


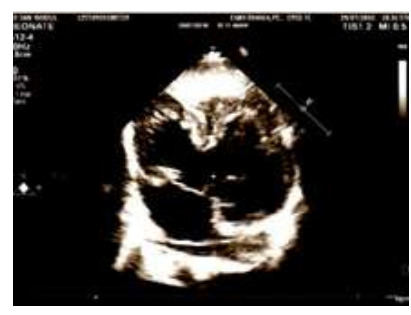

Figure-II: Color Doppler imaging revealed the crossing of the atrioventricular connections. There were concordant atrioventricular connections, morphological left ventricle on the right side.
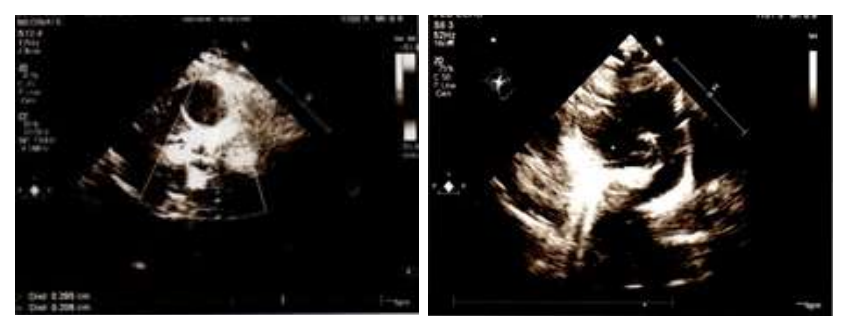

Figure-IV: ShortAxis view shows Figure-V: Echocardiography aorta is anterior and Malposed Showing DORV with PA and and small pulmonary Arteries are Malposed Aorta. getting supply from PDA.

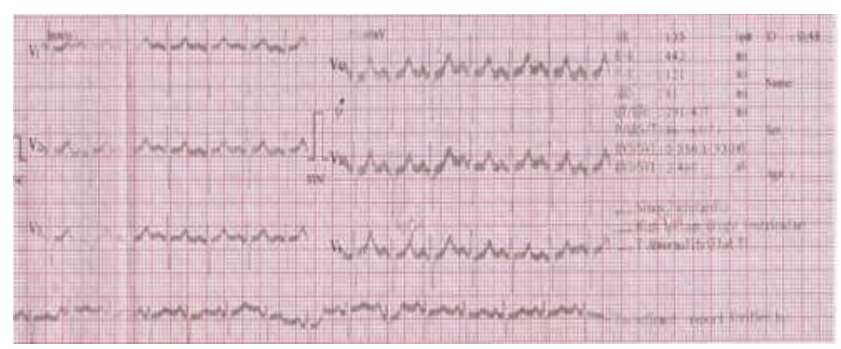

Figure-VI: ECG Showing Right Ventricular Hypertrophy

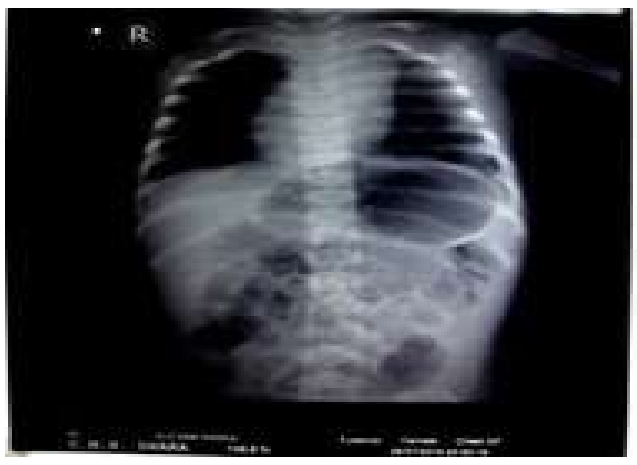

Figure-VII: Chest X-ray Showing MesocardiaNormal sized heartand oligaemic lung Fields

\section{Discussion}

The criss-cross heart is an extremely rare malformation of heart. This congenital defect was first described by Lev. Rowlett in 1961, but it was only in 1974 that Anderson et al ${ }^{2}$ first used the term criss-cross heart. The diagnosis of criss-cross heart is based on crossingof the long axes of the atrioventricular valves. This gives the appearance of each atrium emptying into the contralateral ventricle. Criss-cross heart is almost always associated with other severe cardiac anomalies. The majority of patients with criss-cross heart have hypoplasia of the tricuspid valve and right ventricle, a VSD, abnormal ventricular-arterial alignments (either transposition ofthe great arteries or double outlet right ventricle) and pulmonary stenosis or atresia. Consequently, neonates present with cyanosis and a systolic murmur. Some patients with criss-cross heart have only a VSD with normally related great arteries and present with symptom of heart failure ${ }^{3,4}$. Some patients with criss-cross heart have juxtaposed atrial appendages ${ }^{5,6,9}$, rarely patient present with atrial situssolitus but L-Looped orleft handed ventricles (discordant AV segment) but have AV concordance. Despite segmental situs discordance (atrial situssolitus but L-Loop ventricle) the right atrium is aligned with the right ventricles and the left atrium with the left ventricle. Similarly rare patients with atrial sites solitus and D-Looped or right handed ventricles (concordant AV segmental situs), have AV alignment disorder. That is the right atrium is aligned with the left ventricle. Criss-cross heart illustrates the important concepts that AV alignments in L-loop and D-loop heart are important and both must be elucidated and described independently ${ }^{10}$. Associated defects with criss-cross heart include:straddling mitral valve ${ }^{11-15}$ and tricuspid valve, sub aortic stenosis and aortic arch obstruction, mitral stenosis. Initial management is usually determined by the severity of pulmonary stenosis. If pulmonary blood flow is inadequate, short term palliation with prostaglandin E1 is indicated to maintain patency of the Ductusarteriosus. Then a systemic to pulmonary shunt is created to provide adequate pulmonary blood flow until more definitive surgical management can be undertaken. PDA stenting may also be done.

Echocardiography is the primary diagnostic tool. The diagnosis is made easily in a subxiphoid long axis scan of the heart by showing the crossing axes of the two atrioventricular valves $^{11,13}$. Similarly a scan from posterior to anteriorswiping the apical four chamber view shows the crossing axis of the atrioventricular valves. The great arterial connections are better visualized in the parasternal window. Doppler color flow mapping has been reported to facilitate detection of crossing of the inflow Streams ${ }^{14}$. Angiography can also use for diagnosis. More recently magnetic resonance imaging has been shown capable of detecting the atrioventricular valves and associated defect ${ }^{15-17}$. Prenatal diagnosis can be carried out with fetal echocardiography. The optimal time for imaging the fetal heart is seventeen weeks of gestation.

\section{Conclusion}

The study of this case reflects the structural abnormalities associated with the criss-cross heart, way of presentation, and plan of management. The initial management was planned by creating a BT shunt to maintain pulmonary flow and growth of pulmonary artery. The plan of surgery is determined by the function of both ventricles. In single ventricle physiology, 
Bidirectional Glenn operation can be done followed by completion of a Fortran type operation. Only small minority of these patients are suitable for two ventricle repair because of hypoplasia of the tricuspid valve and right ventricle. For this case surgical repair may be possible in future by placing a conduit from right ventricle to pulmonary artery.

\section{References}

1. Lev M, Rowlett VP. The pathologic anatomy of mixed levocardia. Am j cordial 1961; 8:250-5.

2. Anderson RH, Shinebourne EA, Gerlis LM. Criss-cross atrioventricular relationships producing paradoxical atrioventricular concordance or discordance. Their significance to nomen-clature of congenital heart disease. Circulation 1974; 50(1):176-80.

3. HeryE,Jimenez $M$, Didien $D$ et al.Echocardiography and angiography findings in superior-inferior cardiac ventricles. Am J cardiol1989; 63:1385-9.

4. Sato K, Ohara S, Tasukaguchilyasui $\mathrm{K}$ et al. A criss-cross heart with concordantatrioventriculoarterial connections.Report of a case.circulation 1978; 57:396-400.

5. Anderson RH, Smith A, Wilkinson JL.Disharmony between atrioventricular connections and segmental combinations. Unusual variants of "criss-cross" hearts.J am collcardiol 1987; 70:1274-7.

6. Wienberg PM, Van praugh $R$, Wagner HR et al. New form of crisscross atrioventricular relation: An expanded view of the meaning of $\mathrm{D}$ and L-Loops (abstract). World congress of paediatric cardiology, London 1980, Abstract 319.

7. Otero coto E, Wilkilson JL, Dicjinson DF et al. Gross distortion of atrioventricular and ventriculoatrial relations anociated with left juxtaposition of atrial appendages: Bizarre form of atrioventricularcrisscross. Br heart J 1979; 41:486-92.

8. Wagner HR, Alday LE, Vlad P. Juxtaposition of the atrial appendages: A report of six necropsied cases. Circulation 1970; 42:157-63.
9. Van Praugh. R. When concordant or discordant atrioventricular alignments predict ventricular situs wroughy $\mathrm{I}$. Solitus atria, concordant alignments and L-Loop ventricles. J am coll cardiol 1987; 10:1278-9.

10. Marino B, Sauders SP, Pasquini $L$ et al. Two dimensional echocardiographic anatomy in criss-cross heart. Am J cordial 1986; 58:325-33.

11. Geva T, Van Praugh S, Sanders SP et al.Stradding mitral valve with hypoplastic right ventricle, Dextrocardia, and criss-cross atrioventricular relations: Morphologic, diagnostic and surgical consideration, J Amncoll Cordial 1991; 17:1603-12.

12. Carminati $M$, Valsecehi $O$, Borghi $A$ et al. Cross-sectional echocardiographic study of criss cross hearts and superainferior ventricles. Am J Cardiol 1987; 59:114-8.

13. Fraisse $A$, del nido PS, Gaudant $J$ et al.Echocardiographic characteristics and outcome of straddling mitral valve. J Am Collcardiol 2001; 38:819-26.

14. Han H-S, Seo JW, Choi JY. Echocardiographic evaluation of hearts with twisted atrioventricular connections (criss-cross heart). Heart Vessels 1994; 9:322-6.

15. Igarashi $H$, Kuramatsu $T$, Jhirashi $H$ et al.Criss-cross heart evaluated by color Doppler echocardiography and magnetic resoranceimaging. Eur J Pediatr 1999; 149:523-5.

16. Sato K, Ohara S, Tasukaguchilyasui $K$ et al. A criss-cross heart with concordant atrioventriculo-anterial connections. Report of a Case Circulation 1978; 57:396-400.

17. Danielsai GK,Tabry IF, Rirrer PG et al. Surgical repair of criss-cross heart with straddling atrioventricular valve. J Thoraccardiovasesurg 1979; 77:847-51. 